\title{
A rare case of Burkitt'slymphoma in an AIDS patient presenting as proptosis - a case report.
}

\author{
Kishor K. Satpute ${ }^{1}$, M. Satyabhama Devi ${ }^{2}$,Ibohal Salam ${ }^{3}$. \\ 'Department of Ophthalmology, Regional Institute of Medical Sciences, Imphal, Manipur. $)^{1,2}$
}

\begin{abstract}
A new case of immune-deficiency (AIDS) associated Burkitt's lymphoma presented with proptosis in a young girl is described here.Lid edema,conjunctival chemosis and acute proptosis progressed over 15 days despite of the systemic antibiotic treatment. CT scan of the orbit revealed the mass from left pterygo-palatine fossa, maxillary sinus antrum invading into the left orbit. Histo-pathological examination of the nasal mass sample revealed \"Starry-Sky〉" macrophages typical of Burkitt's lymphoma with the immune-histochemistry markers like CD 10 and CD 19 were negative.A literature review discloses very few cases of orbital Burkitt's lymphoma which is the rare entity in medical literature. Review results shows that can be treated with intensive chemotherapy and HAART. Key-word: Acquired immune-deficiency syndrome (AIDS) ,Burkitt's Lymphoma (BL),Immune-histochemistry, Highly active anti-retro viral therapy (HAART).
\end{abstract}

\section{Introduction:}

A 10- years- old Muslim girl presented to the Ophthalmic Outpatient Department in Regional Institute of Medical Sciences, Hospital, Imphal with progressive swelling and protrusion of the left eye with mild pain, fever with painful papulo-vesicular rash over left arm and 2 episodes of epistaxis through the left nostril. No history of trauma and no loss of vision recorded, no significant past and personal history, but family history revealed that mother died of unknown cause and father is still on prolonged treatment(?ART).For the detail work up, patient was admitted in Eye Ward.

On general examination: Patient was of average Indian built and cachexic. Other parameters were found normal except papulo-vesicular rash over the left arm and forearm with grouped vesicles. Systemic examination was within normal limit (WNL).

\section{On ocular Examination:}

On presentation Left eye(L/E) shows(fig.1) Ecchymosis, erythema, tense upper lid with proptosis of the eyeball (forward and outward ). Palpebral fissure widened measuring $15 \mathrm{mmvertical}(\mathrm{N}=8-10 \mathrm{~mm}), 35 \mathrm{~mm}$ horizontal $(\mathrm{N}=25-30 \mathrm{~mm})$ and lagophthalmos about 3-4mm.Conjunctiva was congested and chemosed, while the other eye structures such as Sclera, Cornea, Anterior chamber,Iris, Pupil, Lens and Fundus were within normal limit. Ocular movements of L/E were restricted in all directions of gaze, Visual acuity-R/E:6/6,L/E: 6/9;Intra ocular pressure (Schiotz)-R/E:15.9mmHg and L/E: $14.6 \mathrm{mmHg}$ at the time of admission. Right eye examination was normal . Proptosis measurement was done with Hertel's exophthalmometer and found $23 \mathrm{~mm}$ on L/E compared to $12 \mathrm{~mm}$ on R/E. On follow up examination after two months condition worsened involving both eyes with severe proptosis measuring $30 \mathrm{~mm}$, severe soft tissue involvement with chemosis and congestion ,severe corneal involvement with exposure keratitis epithelial breakdown and stromal melting. Extraocular movements were restricted in all direction of gaze and Light perception was lost in both eyes.

On investigations-Hb-9.8 gm/dl,ESR-105 mm/1 sthr, while TLC, DLC, platelet count,blood sugar,liver function test, kidney function test,serum electrolyte, HBs-Ag,HCV-Ab tests were found normal. Patient was found to be positive for HIV-1 test with Bioline,Triline,and Tridot with CD4 count-226 cells/cumm, CD3 average 115 cells/cumm. Electrocardiogram,chest X ray were WNL while the X ray PNS and left Orbit -AP shows absence of normal air shadow on the left nostril and orbit suspecting some mass .

CT orbit coronal and axial view(fig.2) shows large well defined mass with irregular margins involving the left pterygo-palatine fossa ,maxillary sinus antrum and extending to the orbit and upper part of the left nostril; the mass seen pushing eyeball linferiorly suggesting inverted papilloma, sq. cell carcinoma of PNS or rhabdomyosarcoma.

Histopathological examination(HPE)(fig.3) from the left nasal mass shows diffuse sheets of large pleomorphic lymphoid cells with prominent nucleoli vesicular chromatin and irregular clumps, features of nuclear moulding with high abnormal mitotic figures, cytoplasmic vacuolations and numerous "starry-sky" macrophages, the normal respiratory type epithelial lining and subepithelial vascular loose connective tissue infiltrared by lymphonodular inflammatory cells; the features consistent with extranodal Burkitt's lymphoma(AIDS associated). 


\section{Discussion-}

Proptosis is the abnormal forward displacement or protrusion of the eyeball ${ }^{1}$. Orbital cellulitis is commonest cause of unilateral proptosis in children with the eccentric lateral globe displacement, while metastatic tumours, rhabdomyosarcoma, nasopharyngeal tumours can also be considered.

As given in literature, the relative frequencies of different orbital tumours in patients of 15 years of age and younger include Dermoid cyst 35.1\%, Hemangioma 9.1\%, Rhabdomyosarcoma $8.8 \%$ and Optic nerve glioma $6.1 \%$ respectively ${ }^{2}$.

Burkitt's lymphoma is an uncommon type of Non-Hodgkin's lymphoma (NHL) with incidence in adult $<1 \%$ of NHL and up to $30 \%$ of childhood NHL. Burkitt's lymphoma is recognised by the typical "starry-sky" macrophages. There is very high incidence of the disease in equatorial Africa (Endemic Burkitt's lymphoma). Disease in other region of the world is much less common, and is called sporadic Burkitt's lymphoma .There are three distinct clinical forms of Burkitt's lymphoma.

Endemic Burkitt's lymphoma- It is common in equatorial Africa, children>adults,95\% related to Epstein-Barr Virus (EBV) infection. It commonly involves jawbone and abdomen. Sporadic Burkitt's lymphoma- It affects rest of the world other than Africa. In children it is less commonly associated with EBV, >90\% typically presents as abdominal mass. HIV- associated immunodeficiency Burkitt's lymphomais the second most common AIDS-related lymphoma. Orbital involvement has been rarely reported in any subtype of Burkitt'slymphoma ${ }^{3}$.

Werutsky $\mathrm{G}$ et $\mathrm{al}^{5}$. Sao Lucas Hospital, Brazil,recently reported a case of 29 yr.old women diagnosed as AIDS presenting with chronic sinusitis, and biopsy discovered sinonasal Burkitt's lymphoma in early stage, which is a rare entity in medical literature. Edelstein $\mathrm{C}$ et $\mathrm{al}^{6}$. Ocular Oncology Service, Wills Eye Hospital ,Philadelphia,USA, reported an unusual case of Non-African Burkitt's lymphoma presenting with oral thrush and an orbital mass in an immune competent child. Bakers PS et al ${ }^{7}$.Wills Eye Hospital, USA, reported 3 cases of orbital Burkitt's lymphoma in immune competent patients. Prall FR et al ${ }^{8}$. Rocky Mountain Lions Eye Institute, Aurora, USA, reported a case of rapid onset proptosis and visual loss as the initial presentation of Burkitt's lymphoma.

\section{Conclusion-}

This case is reported because Burkitt's lymphoma in immune compromised (AIDS) patient arising from respiratory mucosa is a very rare presentation of proptosis which can be treated with intensive chemotherapy and HAART. Patient was on HAART but Specific treatment for Burkitt's lymphoma was deferred because of patient denial and unfortunately patient died due to aggressive nature of disease.

\section{References-}

[1] Sihota R, Tandon R. Parson's diseases of the eye20 th edi.New Delhi:Elsevier;2007.p 454.

[2] Harley RD.Pediatric ophthalmology $2^{\text {nd }}$ edi.Philadelphia:W.B.Saunders company;1983.p1247.

[3] Longo D. Malignancies of lymphoid cells .In Fauci A, Braunwald E ,Kasper D, Hauser S, Longo D, Jameson J et al.Editors.Harrison's principles of internal medicine $17^{\text {th }}$ Edi.USA:Mc Graw Hill;2008.p 687-700.

[4] Werutsky G,Pereira de CarvalhoG , Duval da Silva V,Garicocheaa B. AIDS-related sinonasalBurkitt's lymphoma successfully treated with intensive chemotherapy regimen and high active antiretroviral therapy . HematolOncol StemCelTher 2011; 4(1): 41-44.

[5] Edelstein C, Shield J, Shield CL, De potter P, Eagle RC,Turtel et al. Non-African Burkitt's lyphoma presenting with oral thrush and orbital mass in a child. Am J Ophthalmol 1997 Dec;124(6):859-61.

[6] Bakers PS, Gold KG, Lane KA, Bilyk JR, Katowitz JA.Orbital Burkitt's lymphoma in immuno competent patients: a report of 3 patients and review of liturature.Ophthal plast Reconstr Surg.2009 Nov-Dec:25(6):464-8.

[7] Prall FR, Hink EM, Liang X, Durairaj V.Rapid onset proptosisvision loss as the initial presentation of Burkitt's lymphoma.Ophthalmic Surg Lasers Imaging.2008 Jul-Aug;39(4):331-4.

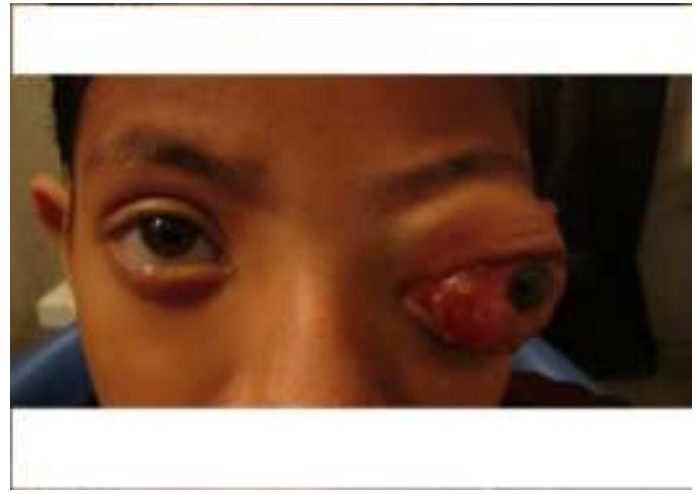

fig. 1 proptosis $(\mathrm{L} / \mathrm{E})$ on initial presentation 


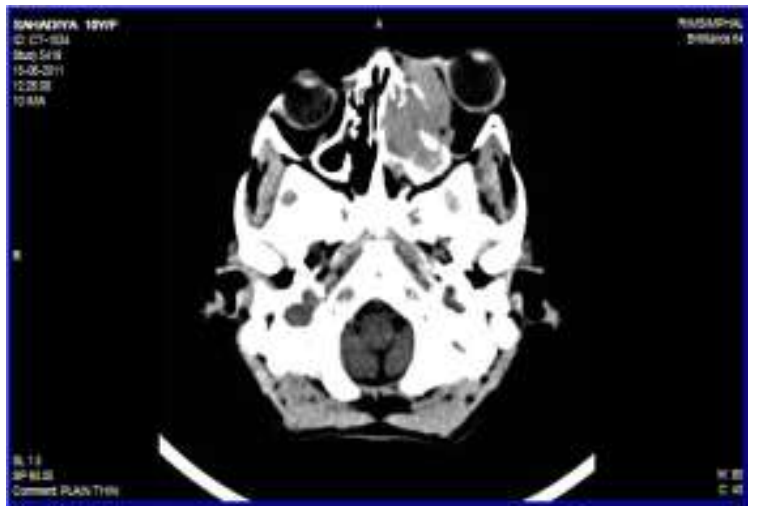

Fig.2CT Scan orbit axial view -largewell defined mass involving left pterygo-palatine foss, maxillary antrum,upper part of the left nostril extending to the left orbit.

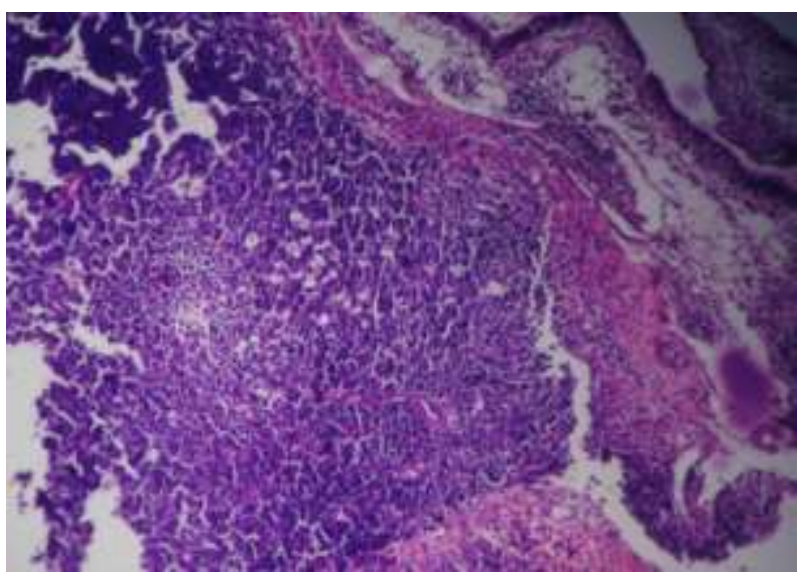

Fig.3HPE-shows respiratory epithelial lining,diffuse large pleomorphic lymphoid cells and numerous 'starrysky'macrophages.

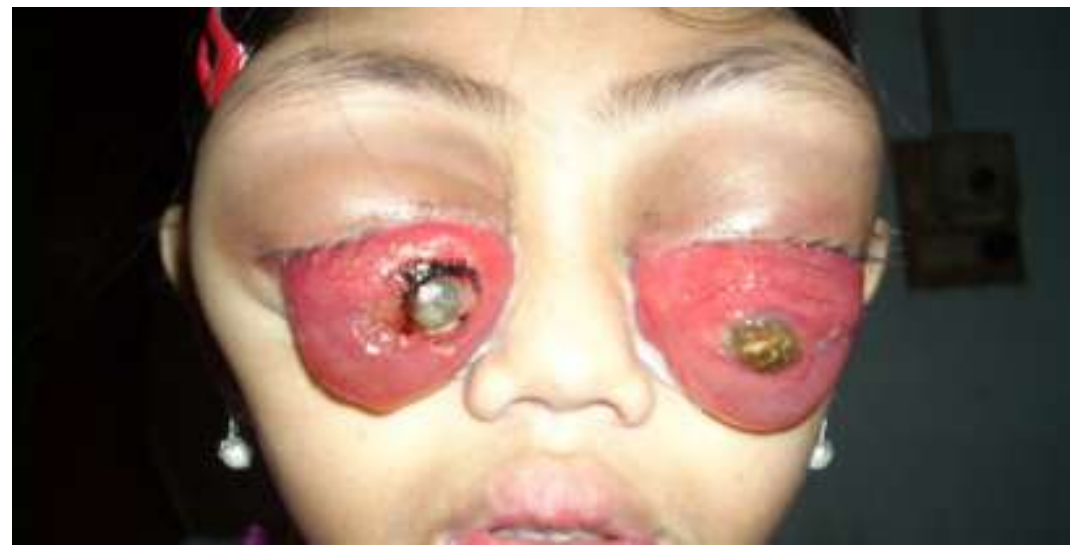

Fig.4- Two months after the initial presentation involving both eyes. 